\title{
THE ELEMENTARY TEACHER AS A MANAGER IN THE CLASSROOM
}

\author{
Venelin Terziev ${ }^{1}$
}

\begin{abstract}
The present work seeks to answer what are the appropriate tools for an effective organization for carrying out a creative learning process. A thorough and critical analysis is made on the functions of the teacher, as the latter is considered from the position of a manager in the study (class) room. Emphasis is placed on the study of the process of adaptation to the school environment, as well as the possible consequences of not implementing that same process. The new social role of a child at school is preceded by a series of attractive external stimuli (clothing, knapsack, textbooks, exercise books, school building), which through their family and kindergarten orient them in the forthcoming comprehensive change of their lives. These external stimuli are not enough for a child to adapt quickly to the rights and obligations at school, as well as to the changed evaluation criteria of their activity, mainly learning.
\end{abstract}

UDC Classification: 37.014.53-053.5 + 316.614-053.5, DOI: https://doi.org/10.12955/pss.v1.81

Keywords: adaptation, manager, education, classroom, teacher.

\section{Introduction}

Preparation of children for school within the contemporary challenging conditions of public development is mainly related to their psychological, physical, moral and social readiness for school. Whereas the psychological readiness is defined through the development of intellectual processes along with the increase of knowledge about reality and cognitive skills of children; whereas the moral readiness is measured by the adult-child, child-child relationships and mainly relies on the development of disciplined behavior of the future students, and physical readiness is characterized by the health and vitality of children, then social readiness generally relates to the new situation of the child in school environment, to acceptance of a new social role of a student, which in reality changes the nature of their relationship with parents, teachers and adults (Petrova, 1989).

The new social role of a child at school is preceded by a series of attractive external stimuli (clothing, knapsack, textbooks, exercise books, school building), which through their family and kindergarten orient them in the forthcoming comprehensive change of their lives. These external stimuli are not enough for a child to adapt quickly to the rights and obligations at school, as well as to the changed evaluation criteria of their activity, mainly learning.

Social readiness for school is related to the development of a number of the child's personal capabilities and qualities, the most important of which are: independence in behaviour according to the types of their relationships with adults and peers, flexibility in the organization of their own lives combined with the ability to overcome difficulties, stability in behaviour, well-being and desire to work. Generally speaking, social readiness is a complex of social capabilities and social behaviour that develop under the influence of purposeful education.

The goal of the present publication is to study the process of adaptation to the school environment, as well as the possible consequences of not implementing that same process.

\section{Theoretical study}

To achieve the objective, complex methods were pursued. For the purposes of the research different information sources were used - scientific journals, publications by Bulgarian and foreign authors, online (electronic) periodicals, as well as the author's own research.

\section{Significant factors in the process of adaptation of a first grader to the school environment}

Social behaviour of an individual still has not received its well-deserved place in contemporary literature. On the other hand, it has not become the goal of modern education, even though the social behaviour of a person combines significant qualities such as sympathy, independence, collaboration, friendship, mutual assistance and responsibility that shape their social maturity.

Social behaviour represents a complex of various actions that reveal the relationships between people in a certain community and arise under the influence of different motives and external stimuli. Social behaviour is defined by social peculiarities. They, in turn, manifest themselves in the child's ability to

\footnotetext{
${ }^{1}$ Georgi Rakovski Military Academy, Sofia, Bulgaria; University of Rousse, Rousse, Bulgaria; Kaneff University Hospital, Rousse, Bulgaria; Russian Academy of Natural History, Moscow, Russia; terziev@skmat.com
} 
deal with other children, to be patient with them, to respond to other people's experiences, to be ready to help if necessary, etc. (Georgiev, 1971).

The formation of social abilities develops in the process of interaction of an individual with the public environment, i.e. in specialized conditions of public education, at kindergarten, at school, assisted by the family (Figure 1).

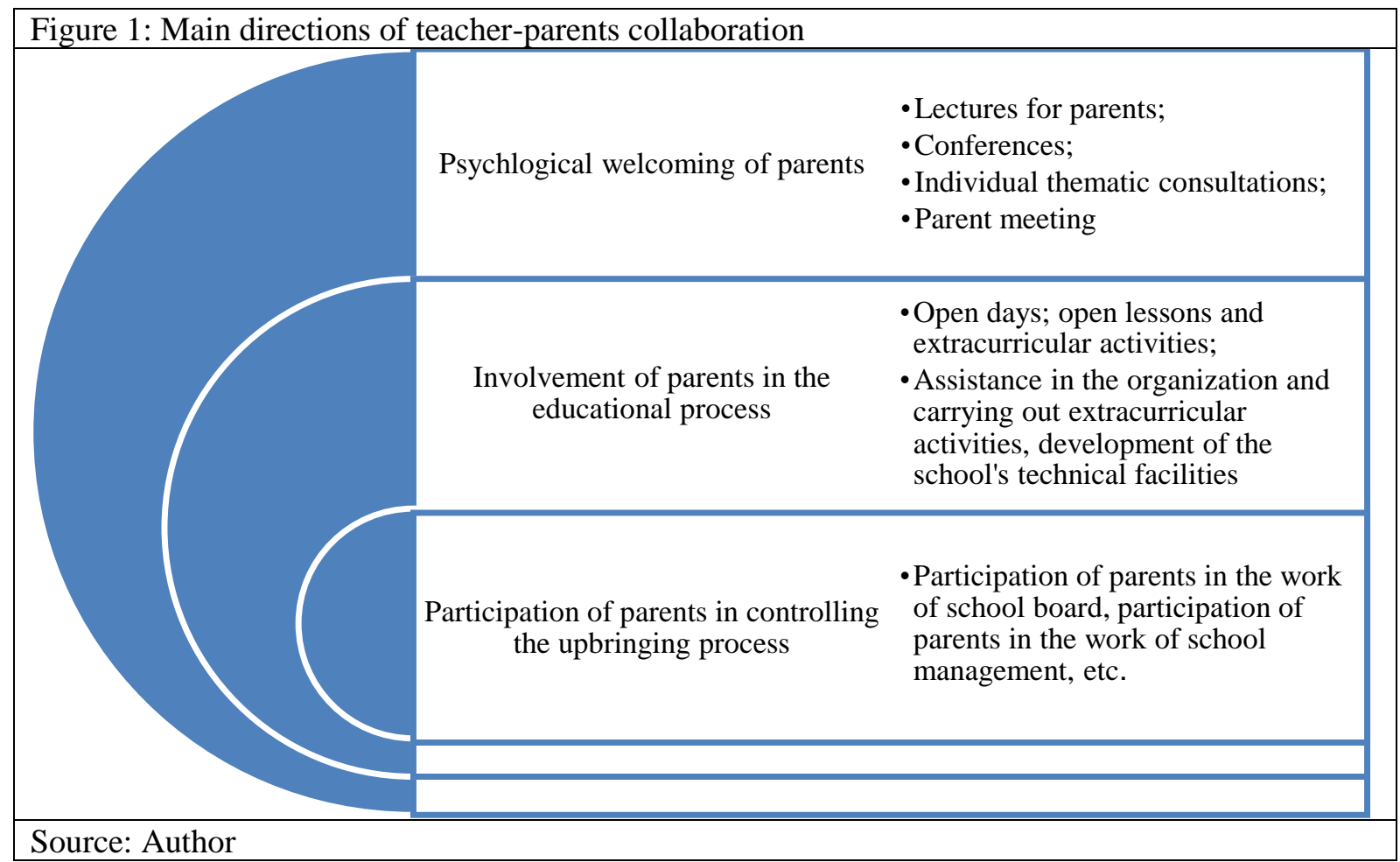

\section{Psychological characteristics of the student's personality in first grade}

Development of a child's personality is influenced by the social conditions and the decisive role of their upbringing. To the question: When a child becomes a personality? - we should answer: When a few grains of sand become a heap! Social conditions in the family contribute to the gradual development of a child's mental soundness, to certain resistance in behaviour towards adults and other children. This is not just a result of the new social conditions of life, but also of the growing opportunity for a personality to make an impact within these conditions. The causes that determine the gradual transformation of a human individual into a personality at the end of early childhood are, at the same time, the causes and the driving forces behind the development of a first grader's personality. The dialectical interaction between development and the conditions in which the child lives gives the most accurate picture of the dynamics of their development.

A first-grader engages in a new type of relationship with others. From a stage of co-working with adults through early childhood and pre-school years, they move on to relatively independent behaviour (Pavlov, 1951). The level of intellectual development of a child enables a first-grader to accept different patterns of behaviour by describing actions or by examples in works of art.

The new type of communication that students establish with each other plays a vital role in their development. The young student does not only have the need to communicate with their peers. When playing or performing tasks with each other, they establish relationships similar to those observed in adults. This way, they develop habits that help them feel part of a society and shape their relations with others based on equal participation in an activity.

The impact of a class on the development of a child's personality is growing significantly. A firstgrader basically learns about the norms of relations with other people, applies them in their relations with other students, adapts the learned rules to various specific situations. In the process of communication, the child realizes their place in the class, which is manifested in the classmates' attitudes towards them. Such a place is extremely important for the right development of a child`s 
personality. Therefore, teachers should purposefully assist in developing the best status for each child, with a view to their proper upbringing and development.

The development of the basic activities such as learning, playing and working is the main factor contributing to a child's personality. Making these activities more diverse and comprehensive determines the development and differentiation of the intellectual, moral, aesthetic and decision making qualities of an individual (Pavlov, 1951).

Such capacities and qualities of a first-grader become more resistant and systematized and are fundamental for a higher degree of social maturity. The most favourable conditions for the social interaction of a child with peers are: by learning, working and playing. These activities are the best at manifesting and developing those traits and qualities of a child's personality and also developing its core and its motivational system. One of the most important conditions for this is the collective organization of the activities, because it creates the greatest opportunities for interaction and communication between first-graders.

Learning activity is of utmost importance for the development of students. Involving children in properly organized learning activity rises awareness of their behaviour and helps understand the emerging traits and qualities of a child's personality.

Through work a young student is actually involved in the activity of adults. Thus, even though it originates from playing, it is a step forward in satisfying the social need for students to participate in the lives of others. The developmental function of the work depends on its gradual complication. Its improvement should be mainly focused on the development of its collective character.

The role and importance of playing activity in the lives of first-graders changes. It becomes dominated by the learning activity when they go to school. However, it continues to play an important role in the lives of elementary school students.

The motives of a first-grader's behaviour, change their content and structure. With proper organization of the educational process, the changes that occur in the motivation system are very significant.

The most crucial role in motivating students' behaviour is the desire to imitate adults. These motives have great motivational power because they are a psychological expression of the child's need to ensure the best possible relationship with people (Desev, 1998).

Motives related to the interest in playtime itself are important to the behaviour of first-graders. They are defined by students' behaviour that comes from their certain role in a game. The strength of the motives is explained by the attractiveness of the game and by the fact that children feel themselves confident as equal participants of social life. At that age, development of cognition, curiosity and competitiveness begins.

Moral motives are of particular importance in the development of a first-grader's personality. Younger children are more willing to perform moral actions towards those adults (Nikolov, 1980a) and peers to whom they feel sympathy.

A child starts school with developed sensory organs. Based on that, the development of a child's feelings that began in the previous ages continues.

Visual sensations play a huge role in the pedagogical process, because through them students receive nearly $80 \%$ of the information about reality. In addition to distinguishing the primary colours, children have the ability to capture colour shades. The development of visual acuity is particularly impressive.

Auditory sensations develop dynamically together with the process of learning to read and write. Thus, it is difficult for us to differentiate purely auditory sensations. Rather, we can talk about auditoryvisual, auditory-motor and other sensations.

Motor sensations develop in several ways. Above all, accuracy and correctness are enhanced. The development of motor habits is accomplished in rather a short time. It is easier for young children to perform general movements associated with walking and running, and fine movements like drawing, sewing, etc. are more challenging for them, resulting in more inaccuracy. They develop qualities such as dexterity, agility, flexibility, mobility, grace and so on. The motor sensations also develop through games: playing with toy cars, sledding, skating, hiding and so on (Amonashvili, 1996). 
As a result of including a first-grader in new activities at school and new requirements, their memory gradually develops and improves, they develop involuntary memory, meaning that they easily learn many things without specifically paying attention to them.

Their memory becomes activated and from the rich variety of surrounding things, students remember the thing that gives them the strongest impression. They memorize directly through action, effortlessly, without the set task or purpose (Filipchuk, 1980).

In first grade a child is asked to remember facts, numbers or rules. The child needs to activate their voluntary effort in order to remember the necessary information successfully and consciously. Therefore, children together with the involuntary memory start to develop the voluntary one. They can memorize voluntarily the defined requirements and orders given to them by adults, mainly teachers.

The memory of a first-grader is enhanced mainly by the requirements related to learning. The students find themselves in a classroom setting, where the teacher daily teaches them, sets certain performance requirements, which become an objective prerequisite for memory development. In order to successfully cope with their school requirements, the students must learn to manage their memory: remember how to sit at the desk, how to write letters, etc. All this is related to the rapid increase in memory capacity.

Visual memory remains useful at this age. Children memorize certain information better and for longer periods of time. However, educational content consists not only of images, colours, forms, but also of a system of concepts, judgments, conclusions, data and so on. This inevitably leads to the rapid development of verbal and logical memory.

During this period, children develop really fast. They become more active and emotional. Their imagination produces far fewer images comparing to adults', since they have little life experience. Imagination is directly dependent on communication with adults and the involvement of the child in various activities.

In the process of communication, through speech, it becomes necessary to create images that are not related to directly perceived objects and phenomena. For instance, by listening to a fairytale or story, on the basis of their experience and knowledge, the child develops an opportunity to create new sets and combinations of images and that is when their imagination manifests itself (Yonchev, 1972). Development of imagination during communication with adults is related to activation of the sign function of our consciousness, clearly observed during playing and learning. The sign function is performed by replacing one object with another or with their images using verbal signs (words). This period of a child's development is particularly characterized by imaginary pictures that are the key to children's imaginations. They are distinguished by their specificity, clarity, efficiency, changeability and rapid transitivity. The peculiarity of children's imaginary pictures is that they always appear with feelings. These feelings usually create very strong emotions.

Thinking depends on the knowledge the child is gaining and learning itself takes place during thinking while solving numerical problems. Knowledge is not transferred mechanically or neither it is automatically accumulated in the mind of a child during communication with adults. We master it while thinking, which is aimed at developing the connections and relations that exist between, objects and phenomena in reality. Through practical actions we enrich our sensory experience, broaden our horizons and create opportunities to understand not only external but also some internal connections and relations between objects, to reveal some elementary causal dependencies and consequences.

A first-grader gets to know these connections and relations in three forms (Lyublinskaya, 1972a):

- In the form of direct interaction with objects. This is where a so-called visual-thinking process is activated;

- In the form of images - visual;

- In the form of logical reasoning - logical thinking.

The most important function of visual thinking is to obtain basic information about hidden properties of objects. Whereas through perceptions the child learns about the external properties of objects, such as shape, size, color, through visual thinking they recognize some hidden properties of objects and phenomena. 
We can characterize visual thinking by the fact that solving a series of problems is accomplished by the use of images without applying practical actions. Its important feature is the re-creation of the subject from its various perspectives, which appear not in logical but in factual sequences. The emergence of visual thinking is an important step in the development of thinking in general.

The development of logical thinking implies the development of logical operations (analysis, synthesis, comparison, summary) and logical forms (concept, judgment, reasoning, questions), through which we learn of the most essential, hidden causal relations and dependencies.

The logical thinking is a basis for successful thinking, which is a prerequisite for the successful involvement of a child in education, and participation of a first-grader in the learning process, in turn, contributes to its further development.

Involuntary attention is dominant in the life of first-graders. It depends on the development of basic processes of the central nervous system, such as excitation and inhibition. Both these processes and the attention are not yet well developed. Attention is now focused on external stimuli that activate our senses. That is why a child's attention is known as sensory. The child can be focused until a new interesting object appears that grabs their attention. For this reason, children find it difficult to focus on one task for a long time, especially if it is not exciting (Boneva, 1969). Although involuntarily, attention is constantly evolving. It is changing throughout the school year. The development of attention is particularly observed in terms of its properties such as sustainability, volume, distribution and mobility.

The sustained attention of a first-grader is the ability of consciousness to focus involuntarily on various stimuli for a long period of time. For instance, in the beginning students are quickly distracted by fatigue, bad habits or improper upbringing.

Attention volume is still limited, although its capacity is expanding significantly compared to younger children. This is the ability of a child to concentrate not only on one object, but also on two, three or more objects. There has been some progress in the ability to distribute attention between different strands of a certain activity.

Children master attention mobility in the process of various activities. For instance, when they attend physical education class, they successfully transfer their attention from walking to exercising, running, etc. The aforementioned qualities of attention manifest themselves as a whole in the activity of a young student. While evolving one quality contributes to the development of others. The greater the volume of attention, the more distributed it is, and the more developed the quality of distribution, the greater the possibilities of its mobility.

A child's speech as a mean of verbal communication arises and develops during their continuous contact with adults who surround them. It is impossible without the social environment the child lives in.

The most crucial point in the active development of a child and their speech is that they start learning the language, the grammar and reading in their native language at school. This knowledge helps them master the language better, speak well and write competently.

As a result, the child's speech is actively developing in the following directions: enriching the vocabulary and understanding the meaning of the words. Students start mastering the grammar rules, understanding the vocabulary, developing phonemic hearing, the functions of speech and the sense of language (Boneva, 1970).

The child's speech is developing as well, especially their vocabulary. There is a significant increase in their vocabulary during the first year at school. By the age of seven, the child has mastered about five thousand words. They are commonly used, related to activities and household, social life, moral standards, education, culture and so on. Of course, not all children make full use of this variety of vocabulary. The degree of speech development of each child is different. Some children use their active vocabulary to a full extent, while others have a limited capacity of their active vocabulary, although they still are able to memorize a considerable number of words.

The assumption that elementary schooling is the time of most rapid development of human speech is associated not only with an enrichment of the vocabulary. This process is mainly the result of gradual and regular development of literacy: reading and writing. 
When children develop their literacy, their cognitive abilities also improve, their outlook expands, they broaden their horizons about the rich world of literature, science and technology. However, mastering of reading and writing does not only contribute to quantitative increase in vocabulary, but also to a deep meaningful understanding of the meaning of each word. With more communications, the sense of language begins to develop as well. With understanding of the phonetics, vocabulary or grammar of their mother tongue, children not only begin to express themselves correctly, but they often notice mistakes in the speech of others. At no other age can we observe such intense and dynamic development of speech. The acquired knowledge during this period is the foundation for further development of a child.

\section{Kindergarten as an important factor of first-graders' adaptation}

One of the most important tasks of pre-school education is the comprehensive preparation of children for school, because it determines the effectiveness of school education (Forst, 1976). To successfully cope with the requirements of the elementary school, the child attending kindergarten must acquire certain knowledge and skills in such volume and quality that they will serve them as a valuable prerequisite for the acquisition of the first grade material. Apart from this, they should also develop those technical personality qualities that will enable a higher level of intellectual activity.

When children go to first grade, they are supposed to be ready to learn, the practical realization of which requires a theoretical justification of both the problem of school preparation and the closely related problem of continuity between kindergarten and the next educational degree. In fact, preparation for school implies reaching a certain level, that ensures the transition to the new mental and personal traits, necessary for the development of new needs, motives and abilities.

Preparing children for primary education has always been a major problem for teachers and psychologists in our country. A positive side of this preparation is that it never implies developing literacy and performing special program tasks, as well as introducing contents of certain school subjects (Valkovoy, 1959).

Many authors in their works are looking for specific qualities of first-graders in terms of performing common tasks, as well as a means of accomplishing them. For instance, in his work P. Nikolov (Nikolov, 1980) outlines in a spiral model the tasks that kindergarteners solve, which make it possible to complicate these common tasks in elementary school.

The organized learning process in kindergarten, on the one hand, contributes to child development, and on the other hand, it also solves the special task that is to develop elements for learning activity and to assist the transition to school. To learn the lesson content, children need to have acquired general learning skills as they go to school. A situation of an organized structure for performing the training creates conditions for the development of elements of learning activity, which will gradually become leading at school.

The development of learning activities in the situation is related to the learning process and provides its developing functions.

Children develop learnability, which is expressed in their ability to deliberately obtain a system of knowledge, skills and habits. Children learn a system of cognitive actions, without which it would be challenging for them to master the system of mathematical knowledge and skills for connected speech.

In order to acquire certain knowledge, skills and habits, children have to become accustomed to being guided by their tasks.

Solving a task is purposeful and deliberate when it comes to a particular didactic result. Expectation of the result stimulates cognitive activity and subordinates the available experience to the tasks (Forst, 1976). Solving new tasks in a new cognitive situation enhances cognitive activity, stimulates thinking activity and most of all prepares children for the transition from kindergarten to the first grade.

One of the most complicated elements of the learning process is planning the activity. It creates conditions for greater independence, diversity and creativity. For example, a child is encouraged to think in advance about the content of their story or drawing and to put a story title or topic on the picture they are drawing. The development of learning activity involves an assessment of the result. With the help of a teacher, a child participates in the evaluation process. 
Under the direct guidance of the teacher, the elements of learning activity and the acquisition of certain skills described above have been developing in unity. Regardless of the degree of a child's awareness, the knowledge must be organized, purposeful and conscious. It prepares a student for learning at school. The components listed above correspond essentially to the structure of the learning activity presented in the pedagogical literature. P.S. Yakimanska, for instance, points out the following components: needs and motives, learning tasks, their solution, various techniques for their implementation, control and evaluation of learning outcomes, analysis of ways to achieve them.

The development of elements of learning activity leads to early development of systematic ideas and concepts for mastering learning skills that determine the child's mental readiness to learn. The presence of these components creates an opportunity for the child to understand common ways of learning, which leads to mental development, facilitates the solution of learning tasks and provides independence.

In addition to these evolving educational tasks, the situation prepares children for the transition to the lesson and provides overall preparation for school. Children of pre-school age do not perform academic activity. Nevertheless, situations as a form of learning process constitute a didactic system whose components interact and ensure the unity of learning, upbringing and development.

By synthetically combining situations and skills learned, we gradually create conditions to control the interconnection between objects and phenomena, and the basic systematization prepares the transition to the school system. The unity of integration and differentiation create skills for a global approach to learning about the environment, facilitating a common approach to enriching the experience. We should not underestimate the educational opportunities of the situations that children receive through the educational process. Usually, the topic and content of the situation are aimed at getting to know the components of different work processes. It is especially crucial here to emphasize labor as a human need; motives for carrying out the work processes, social significance of the outcome, relationships in work interactions; qualities that people must possess in order to achieve work results and to create material and spiritual values.

In addition to these educational functions directly related to the content of the situation, the tasks that relate to the personal development of the child and determine their progress in the learning process are particularly important. It means we should help develop a desire of a child to learn, solve tasks and follow orders.

Together with the attitude towards the student, the situation contributes to the development of moral readiness for learning at school. By solving specific tasks, the child learns to overcome difficulties, to be patient, persistent and to control their behavior.

As a result of personal development, primarily related to the emergence of a child's desire to learn, to show positive attitude towards learning, an interest in gaining knowledge and to create moral and roleplaying activities for school, children gradually develop a certain level of their moral upbringing. It also provides social and moral preparation for school, which implies love for work, a sense of responsibility and independence.

School-based social preparation involves the use of general teaching functions of the education in order to gradually prepare for school. This readiness is necessary for the creation of motives for learning and a responsible attitude towards duties. Such pre-school preparation partially characterizes the child's social development (Petrova, Sheytanova, Slavova, 1978).

The social development traits that prepare the child for a change of community and their place at school develop during different types of activities - learning, playing and working, ensuring not only the availability of knowledge and development of general mental abilities, but also a positive attitude towards learning and the school.

The problem of personal readiness is one of the decisive factors for a successful change of the position of the child who becomes a first-grader. If a child goes to first grade eager to learn and with a positive attitude towards the teachers and school, they will demonstrate their cognitive activity and curiosity, as well as adapt easier to the new community, united by new goals and objectives. The student, both in and out of the classroom, will take the so-called position of a "participant in the learning process and in the whole life of the school" (Sohina, Tarontaevoy, 1977). 


\section{Conclusion}

Students upgrade their skills and habits when they personally refer to the knowledge they need to acquire and when they self-improve socially and morally. Each child expects to go to school, attracted by the new role of a student. The right personal position depends on their perception of the school and their functions as a student. Therefore, a well-organized preparation is needed at the kindergarten with regular visits to a nearby school (Terziev, Bankova, Dacheva, 2019-a; Terziev, Stoilova, 2019b-c).

The child must be convinced that the way to social participate, like the people they meet, is through school. And the education that will make them like these people is related to life in the student community. This is the second decisive problem along with the organization and management of the cognitive process, to create not only cognitive but also personal motives for behaviour when children enter school. This process is also integral. It takes place in the overall activity of the child and, above all, in the collective forms of learning, playing and working.

A personal attitude towards school combines qualities such as curiosity, love for work, independence, responsibility and duty. Therefore, the positive attitude towards the school as a unity of the program content and an effective educational process is permanent. It is not limited to observation and conversation or just a separate work of art. Attitude towards the school becomes an important task in the implementation of the program content in other topics, which is to get acquainted with the public environment, with different work processes, with the arts and so on.

Developing learning skills in unity with the ability to participate in collaborative activities is also a prerequisite for increasing interest in school life and a willingness for intellectual effort in learning the material. Personality readiness is adequately achieved when teachers create conditions at school that would interest students in learning, and help them experience pleasure overcoming difficulties.

Generally speaking, social adaptation is a state of mental and spiritual equilibrium of the individual towards the social community. The social adaptation takes place where it is necessary to overcome the mental tension in the transition from one situation to another (Dikov, 1987).

Through different activities in the preschool age, children develop the necessary skills and habits related to their social, moral and mental preparation for school. This preparation begins from the early age in the family. The interaction and interconnection between the three types of activities (playing, learning and working) create the necessary conditions not only for mental development, but also for the social realization of the person.

Continuity from kindergarten to school means to educate through games these communicationorganizational skills, which later would become of upmost importance for study and work. In the process of a game, a child reflects some aspects of the adults' life they have previously learned. More important here is not the quantitative information reflected in the game, but the modeling of social situations. The whole educational process in the kindergarten reflects social reality. It manifests itself in the nature of knowledge that children receive about the surrounding world and in the knowledge, skills and habits they develop for living together in the children's community. Children learn norms of behavior, gradually obeying the rules that determine their place. This process is constant and fully implemented in various activities. Through the unity of these activities preconditions are made and the formation of socially important traits that provide opportunities for the complete adaptation of the child at school are attained.

\section{References}

Amonashvili, Sh.,A. (1996). Hello children! How are you, children!, S, 1996.

Boneva, A.D. (1969). Your first-grader, S, 1969.

Boneva, A.D. et al. (1970). Parents and the upbringing of the child in school, S, 1970, S, 1970.

Desev, L.N. (1998). Psychological problems of education, S, 1998.

Dikov, T. (1987). Collaboration between school and family, S, 1987.

Filipchuk, G.D. (1980). Do you know your child, M, 1980.

Forst, V. (1976). The child before going to school, S, 1976.

Georgiev, L. (1971). Psychological problems of elementary school education, S, 1971.

Nikolov, P.(1980a). Problems of moral motivation, S, 1980.

Petrova, E. (1989). Preparing children for school, S, 1989. 
Pavlov, P.I. (1951). Collected Works, V.3, M, 1951.

Lyublinskaya, A.A. (1972a). For the mental development of children, S, 1972.

Petrova, E., Sheytanova, Ts, Slavova, R. (1978). Preparing children for school, S, 1978.

Sohina, F.A., Tarontaevoy, T.V. (1977). Preparing children for school in kindergarten, M, 1977.

Terziev, V., Bankova, D., Dacheva, I. (2019). Approaches in governing the educational processes in schools. // XXII International Scientific Conference: The power of knowledge (11-13.10.2019), Kavala, Greece, Institute of Knowledge Management, Skopje, 34, 2019, 2, pp. 311-316, ISSN 1857-923X (for e-version), ISSN 2545 - 4439 (for printed version).

Terziev, V., Bankova, D., Dacheva, I. (2019a). Theoretical underpinning of the problems related to pedagogical excellence and pedagogical creativity in the initial stage of school education. // XXII International Scientific Conference: The power of knowledge (11-13.10.2019), Kavala, Greece, Institute of Knowledge Management, Skopje, 34, 2019, 2, pp. 411-417, ISSN 1857-923X (for e-version), ISSN 2545 - 4439 (for printed version).

Terziev, V., Stoilova, M. (2019b). Analysis of the system of school education. Strategy settlement process. // 21 st International scientific conference: The teacher of the future, Budva, Montenegro, (07-09.06.2019), Institute of knowledge management - Skopje, Macedonia, 31, 2019, 6, pp. 1851-1857, ISSN 1857-923X (for e-version), ISSN 2545 - 4439 (for printed version).

Terziev, V., Stoilova, M. (2019c). Experience of SWOT analysis in the system of the Bulgarian education. // 21 st International scientific conference: The teacher of the future, Budva, Montenegro, (07-09.06.2019), Institute of knowledge management - Skopje, Macedonia, 31, 2019, 6, pp. 1887-1893, ISSN 1857-923X (for e-version), ISSN 2545 - 4439 (for printed version).

Valkovoy, E.I. (1959). Kindergarten School and Seed, M, 1959.

Yonchev, V.A. (1972). The family and upbringing of the child, S, 1972.

Zaporozhets, A.V., Elkonin, D.B. (1966). Psychology of preschool children, S, 1966. 